\title{
Students on board: designing a board game for $1000+$ students
}

Sarah Leach, Geraldine Foley, Jose Javier Olivas Osuna, Aggie Molnar

London School of Economics and Political Science

\section{Keywords: Game-based learning, Higher Education, Board games, Strategy, Economics.}

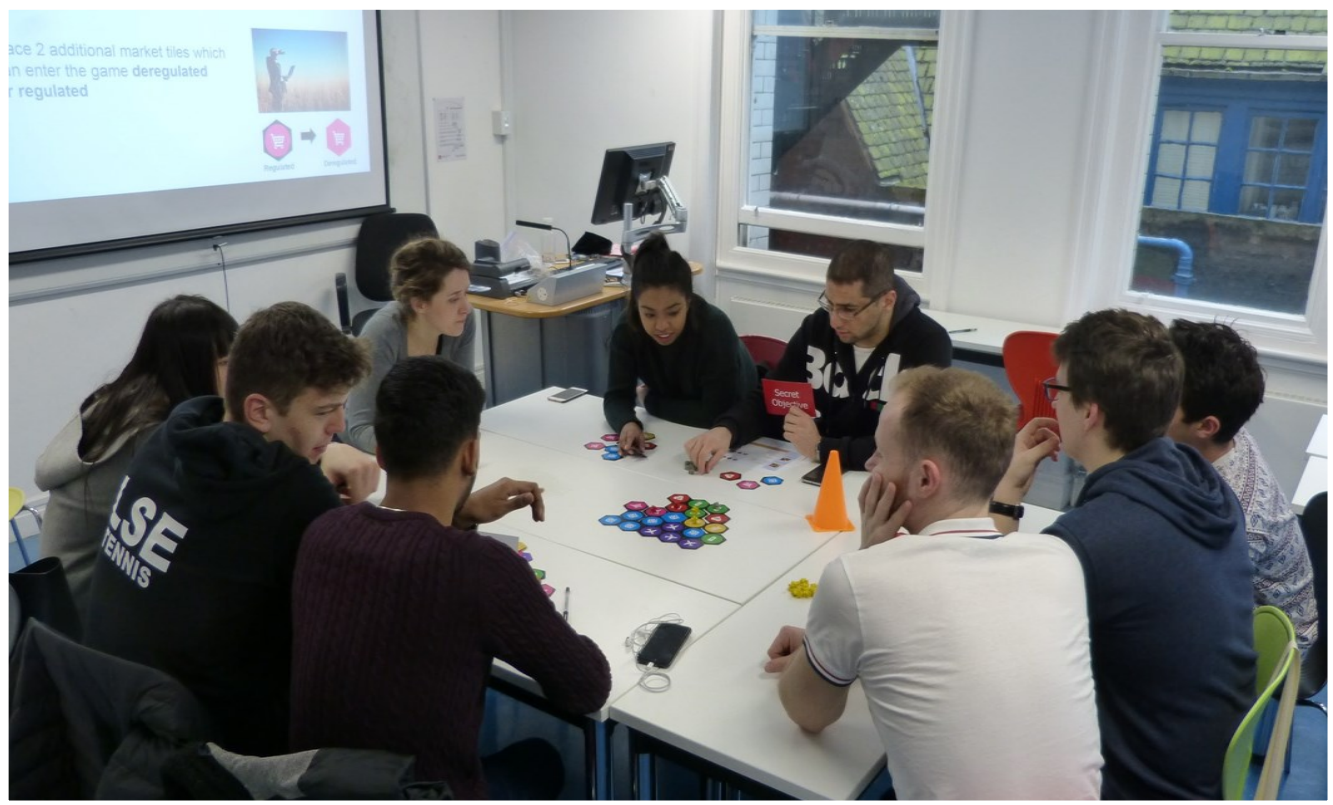

\section{Introduction}

This case study provides a brief overview of our experience of designing a serious game for a large inter-disciplinary course at The London School of Economics and Political Science (LSE). The game was developed with the aim of enhancing student engagement on a course with a mixed-ability cohort. We present the pedagogical rationale and the challenges of designing games for educational purposes and provide both the details of the learning objectives we aimed to fulfil through the game and the findings from the evaluation process.

\section{Context of the project}

The project, funded by an LSE Learning Technology and Innovation (LTI) grant, was initiated and supported by an LSE100 teacher, Dr José Javier Olivas Osuna, in collaboration with Sarah Leach, Geraldine Foley and Aggie Molnar from the LSE LTI team.

The grant was awarded in the summer of 2016. However, as the game was developed at the same time as the module, the specific learning objectives and course materials were being debated until September. Considerable time was spent on game designs - with varying learning objectives - that would later be abandoned. This left only four months to design and play-test the final tile-laying game, as well as to produce the instruction material and game 
components, ready to facilitate teacher training in January 2017. The game was played in 137 classes, over a period of three and a half days, in early March 2017.

'LSE100: the LSE Course' is a compulsory first-year course for all LSE undergraduates and comprises four modules. Classes on LSE100 require students to work outside their discipline with a limited amount of contact time. Since this course does not count towards students' degrees, there is some challenge in securing their engagement with course materials and their commitment to preparation for class. The game 'Capture the Market' was designed to reinforce some of the key concepts from the module in an enjoyable, engaging and accessible way, by encouraging critical thinking via the game's interactions and requirements to make choices. (See Appendix 1 for a detailed list of objectives.)

\section{Pedagogical rationale}

Experiential learning via games has been found to have a positive impact on conceptual understanding, skill development and student motivation (Felicia, 2011). Games can provide a risk-free environment to practise skills, apply knowledge and get feedback (Kafai and Burke, 2015). Although it is important not to assume that games are intrinsically motivational (Whitton, 2010) they can often "make learning fun" (Kirriemuir and Mcfarlane, 2004:4) and motivate disengaged learners (Griffiths, 2002, and Squire, 2008, cited in Plass, Homer, Kinzer, 2015).

The game was designed in accordance with a constructivist approach to teaching, which views learning as an active, contextualised process of constructing knowledge rather than acquiring it (Vygotsky, 1987). It was created to be played at the end of a newly-developed module entitled: 'Should Markets be constrained or unleashed?' This module examines the economic principles of free markets and the case for government intervention and introduces the meta-framework of 'agency, structure and ideas' (Figure 1).

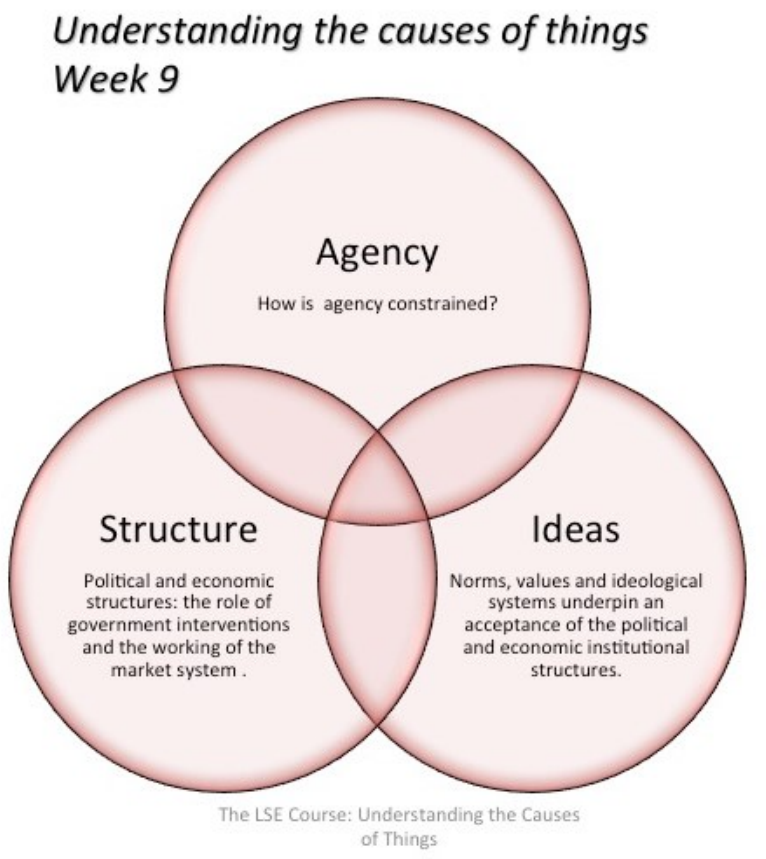

Figure 1: Meta-framework of 'Agency, Structure and Ideas' 
The main learning objective was to develop an understanding of free market mechanisms and the features that enable or constrain the effective working of the market and our agency within it. The game provided opportunities to apply knowledge from the course lectures and readings and facilitate the abstractions needed for knowledge to be generalised to novel situations. In the post-game discussion, students were required to analyse the game mechanics and strategies to reinforce and improve their understanding of the 'agency, structure and ideas' framework.

\section{The game}

'Capture the Market' is a competitive tile-laying game for four to twelve players, incorporating techniques and mechanisms from modern board-game design to illustrate the dynamics and limitations of markets and economic liberalisation. (See Appendix 2 for the design features.) The look of the game was inspired by an open-source game called 'Datopolis', created by the Open Data Institute. Teams build the 'board' by placing hexagonal tiles (Figure 2), which represent the market. The game is played in rounds and in each round the teacher presents new 'government interventions'.

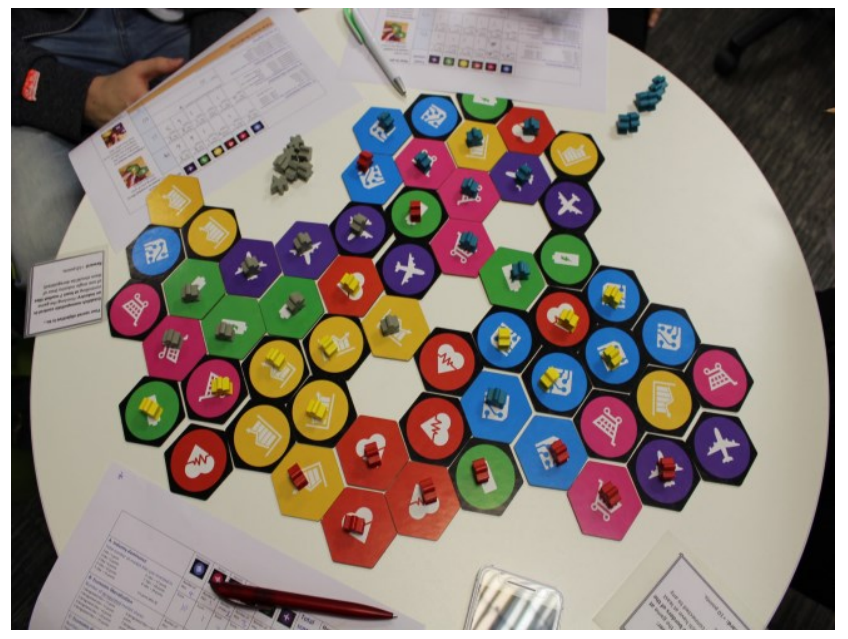

Figure 2: 'Capture the Market' Game

Players gain points according to such criteria as control of an industry and diversification of investments. Additionally, each team is given a 'secret objective' card (Figure 3) that provides another way of obtaining points during the game and helps to guide those who struggle to define their strategy in the game. For example, 'Your secret objective is to....promote protectionist laws'. 

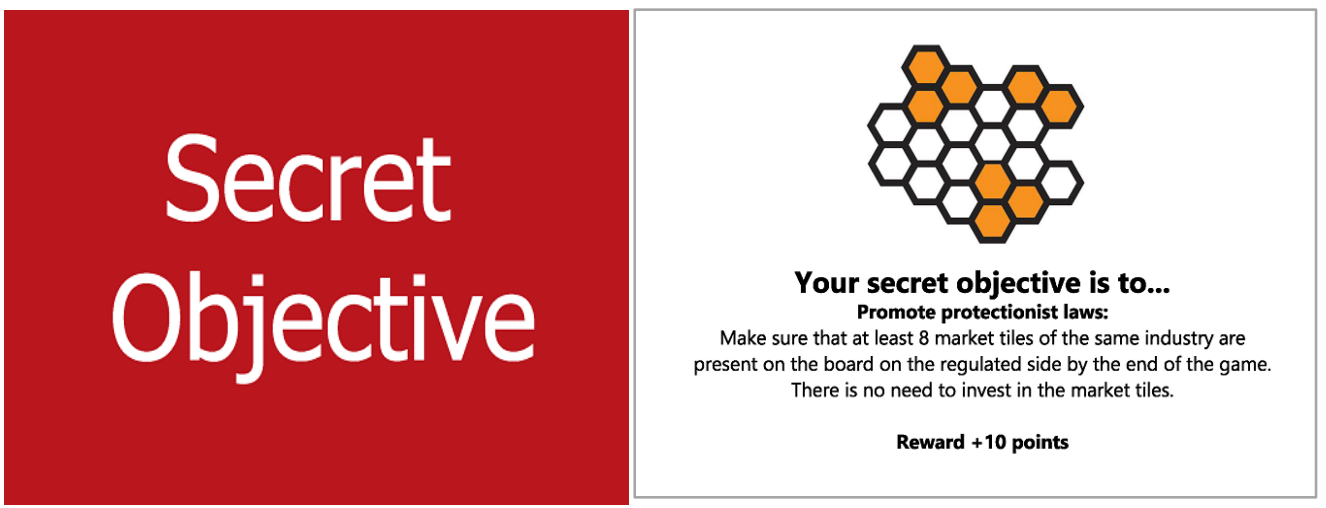

Figure 3: Secret Objective Card

Twelve hexagonal tiles are distributed randomly to each team and the placing of the tiles entirely depends on the players' 'secret objective' and the 'government interventions'. Counters (in four different colours) represent each team's 'ownership' of a tile and players/teams are allowed to invest only in counters adjacent to their other counters, unless otherwise specified by the 'government interventions'.

During the game, 'government interventions' allow players to flip tiles on the board. This represents a market changing from 'regulated' to 'deregulated' status or vice versa (Figure $4)$.

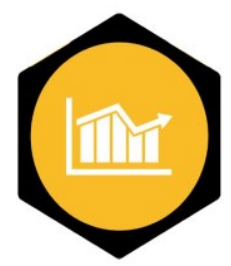

Regulated

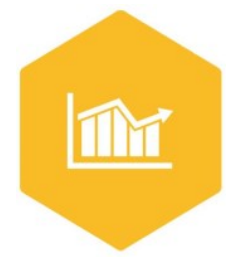

Deregulated

Figure 4: Regulated and Deregulated Tiles

Each game was designed to be explained and played in thirty-five minutes, leaving fifteen minutes for a post-game debrief and discussion.

\section{Design process and challenges}

In addition to the challenges involved in embedding the game into a new module, the most significant obstacles were: timing; finding a good balance between sophistication and accessibility; the large-scale nature of the course.

Timing was difficult because classes ran for just fifty minutes, meaning that the game, including time for instructions and point scoring, was limited to thirty-five minutes to allow for class discussion. The onus was very much on the teacher, not only to lead and draw out the learning objectives of the game, but to keep the game fast-paced. To support teachers, we created a video explaining the rules of the game and sent it to students ahead of classes, as 
well as playing it at the start of every class. Teachers were provided with detailed notes containing timings, instructions for the game and discussion guidance.

The task of creating an engaging thirty-five-minute game - aiming for a state of 'flow' (Csikszentmikalyi, 1990) or student's zone of proximal development (Vygotsky, 1978) - that was both easy to understand and play, yet complex enough to be enjoyable, was challenging. Playtests allowed us to gain feedback and make adjustments, such as highlighting the effects of 'economies of scale' and 'diminishing returns' in the scoring system.

The large cohort of LSE100 students, approximately 1500, were taught in small class groups (maximum twelve students) by a team of thirty-two teachers. Training the teachers, some of whom were sceptical about the benefits of game-based learning, proved to be a challenge. Though optional game-playing sessions were also set up to help teachers familiarise themselves with the game, only a few teachers attended them. The minimal time allocated to the final, mandatory training sessions meant that not all teachers going into class felt confident about the game. Teachers were also offered additional support to facilitate the game in class; a considerable number accepted.

To ensure that teachers were able to manage the game effectively, only one game was played in each class and students were split into four teams of two to four players. This gave flexibility for varying class numbers and helped with the mixed ability of the cohort, allowing students to use peer discussion and feedback to discuss their tactics.

\section{Evaluation}

Several forms of evaluation were carried out: the design team observed thirty out of 137 classes, with twenty different teachers; questionnaires were completed by 112 students (less than $10 \%$ of those who played the game) and fifteen staff ( $47 \%$ of teachers who taught the game); four students attended a focus group session; teachers provided their own observations and feedback after classes on the course's VLE discussion board.

\section{Class Observations}

We observed thirty of the 137 classes and saw a great variation in teaching delivery: different interpretations of the rules; teachers' encouraging 'thinking' time between rounds whilst others kept the game fast-paced; time spent reflecting on readings/links to concepts during the game versus pure game play; variations in game timing, which affected the length and quality of the post-game discussion.

An unexpected observation was the discovery that one teacher could not differentiate between two of the counter colours. Fortuitously, we were supporting this session and were able to offer alternative colours before play began. We had tried to foresee this issue by choosing colours that were considered accessible.

\section{Student survey}

The survey was distributed a week after the last game was played in March 2017. 112 students filled in the questionnaire, which comprised both closed and open-ended questions 
(see Appendix 3). Since the number of responses received was small, it was not possible to derive conclusive data from them. However, the survey reveals some commonalities worth mentioning.

The majority of the students (83\% of the respondents) indicated that they enjoyed playing the game; they highly appreciated the element of 'fun' and the social aspect as well as the opportunity to interact and work in groups: "It is helpful to look at the topic of markets from a different perspective. And though we are not children anymore, learning through playing still works". Several positive comments referenced the "chance to strategise", "visualization of concepts" and "playing against my peers". Moreover, most students felt that the game stimulated decision-making.

More than half of the students agreed or somewhat agreed that the game connected with the module's framework of 'structure, agency and ideas' (Figure. 5), and that it helped them to think about the key concepts of the module (Figure. 6).

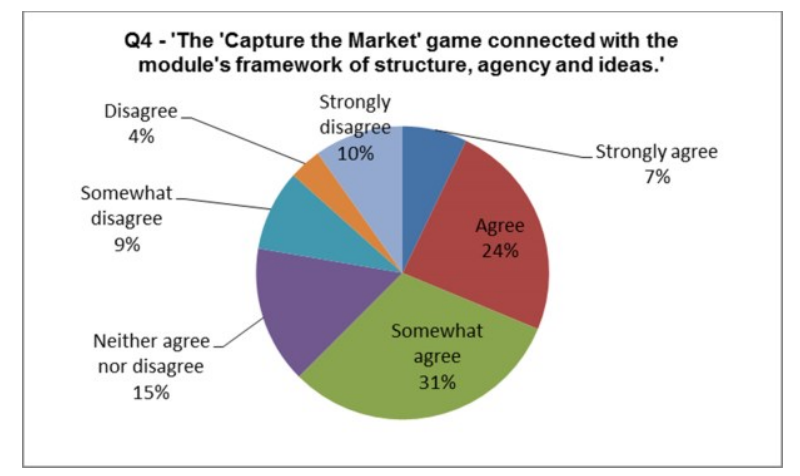

Figure 5: Student Survey Results (a)

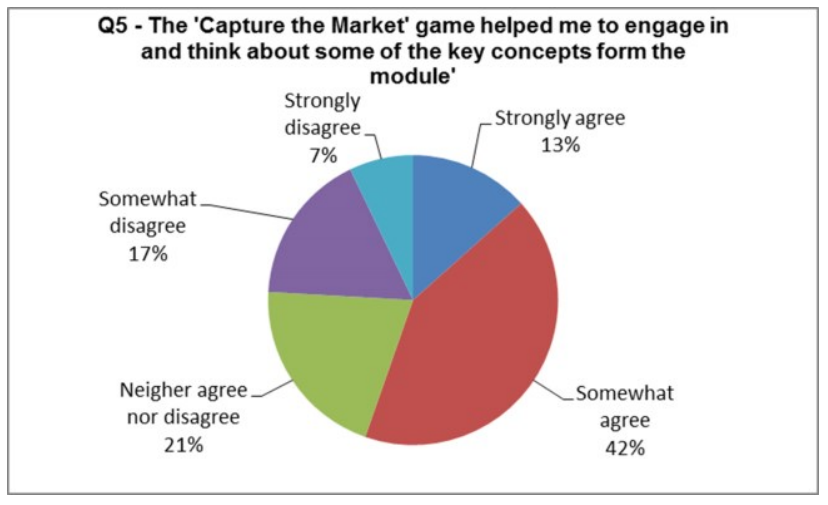

Figure 6: Student Survey Results (b)

The free-text comments showed a less positive assessment of the game's usefulness; they suggested that although the game helped students to think about the key concepts in the course, it did not necessarily help them understand those: "While the game did involve the key concepts from the module, it merely identifies them, rather than providing insight or explanations into how they might actually affect the entrepreneur or the market in the real world". 
Furthermore, although the majority of students agreed that the game was an appropriate activity in the context of the module, follow-up comments revealed that some students deemed it "appropriate but not necessary". Other negative comments further questioned the usefulness of playing the game and its relevance to their studies. However, this could have also reflected students' dissatisfaction with the compulsory course in general: "[l] felt it was a waste of time when I could have been doing work/revising towards my actual degree".

As for recommending the game to be played by next year's cohort, almost $90 \%$ of the students responded positively. Further improvements, such as making stronger connections between the game and the course material or using the game as an ice-breaker activity were also suggested.

Unfortunately, we experienced difficulties in getting students to attend focus groups to gain more qualitative data. The comments of the four students who did attend reflected the findings of the survey in that they enjoyed the game but did not necessarily think that it helped them gain a deeper understanding of the concepts from the module. They also reinforced our observations that students had very different experiences of playing the game according to their respective teacher's management of the class. A few of the participants questioned the appropriateness of using games for learning in their degree courses (rather than in an additional course); this might be an interesting topic to investigate further.

\section{Teacher survey}

The teacher surveys were distributed at the same time as the student ones. Out of the thirtytwo teachers delivering the game, fifteen responded. (See Appendix 4 for staff survey questions).

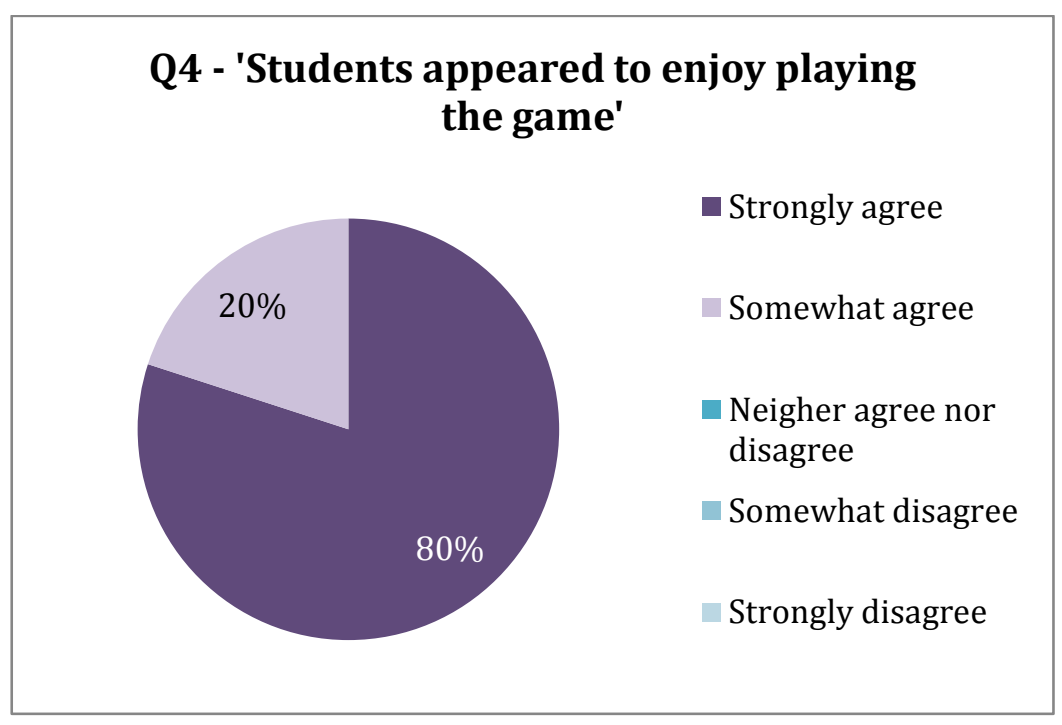

Figure 7: Teacher Survey Results (a)

In accordance with the findings of the student survey, most teachers strongly agreed that the students appeared to be enjoying the game (Figure 7). The following comment from a teacher conveys a description of the change in the students' level of engagement throughout the game: 
"I did see some skeptical faces and a few groans when students first entered the room and saw the game materials being set up; however, by the end of the classes, students seemed quite pleased with how the class had unfolded and often left the room chatting among themselves about their strategies and scores."

The teachers found that students were particularly engaged when the game was played in pairs or teams (as opposed to individual players). Also, many reported that "students easily adopted a competitive dynamic" and that "they were excited, involved and chatty".

Despite the successful engagement with the game and the lesson, some teachers had doubts as to whether the game had increased the students' level of engagement with the module itself: the shortness of the learning experience and the limited depth of some discussions were mentioned as aspects which might have hindered students from linking the game to concepts. Nevertheless, one teacher thought: "the game will provide an interesting and useful example/illustration/case for them to think about when considering the essay question and the module as a whole."

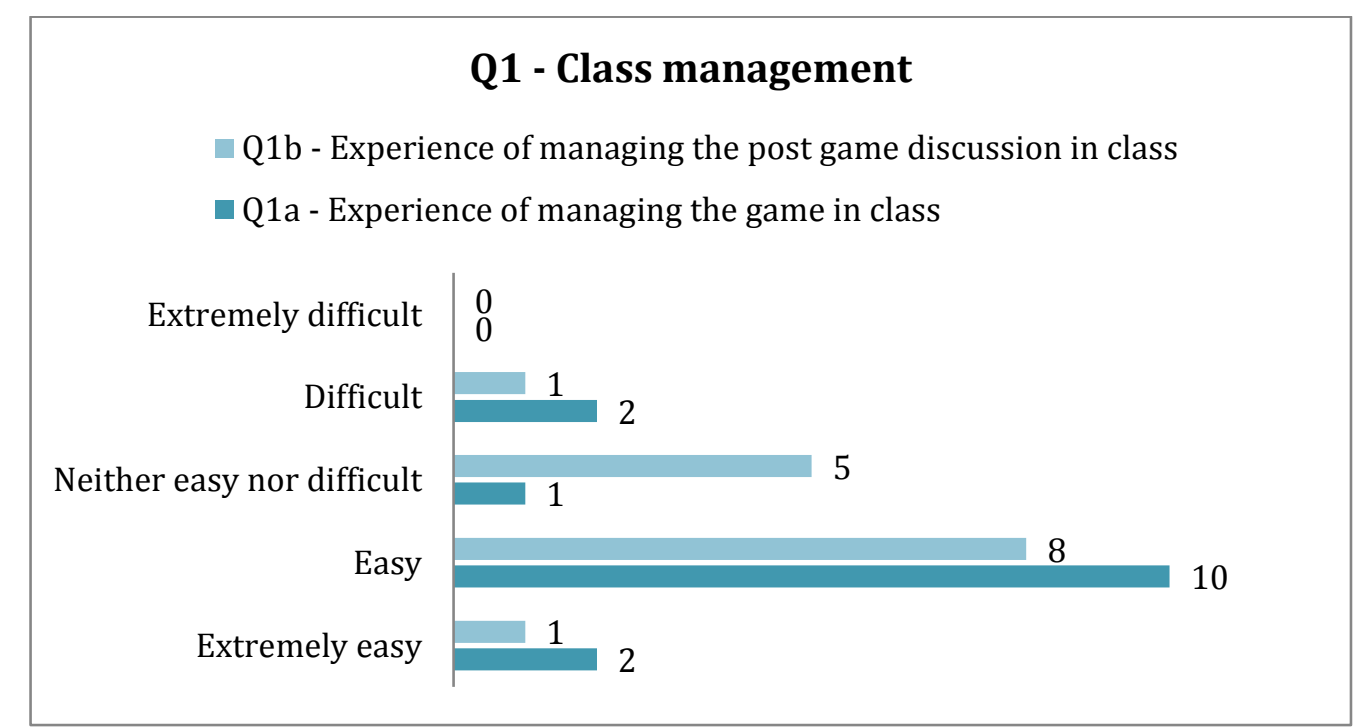

Figure 8: Teacher Survey Results (b)

Managing the class involved explaining and running the game as well as facilitating the class discussion. The majority $(80 \%)$ of the teachers reported that they had found managing the game easy and straightforward (Figure 8) and said that having both the chance to play the game multiple times and the additional support offered by LTI did help to reduce anxiety: "I wasn't sure if I would remember the nuances of the game, and knowing that we had to move fairly quickly, it helped that I had a facilitator". Only two teachers indicated that they had encountered difficulties: one referred to standing/walking whilst facilitating the game, whilst the other did not state a reason. As for managing the post-game discussion, the majority found it 'easy' and one third of the teachers responded: 'neither easy nor difficult' (Figure 8). 
Although most teachers did not find the game or the discussions difficult to run, several teachers noted that they had found it challenging to create a smooth transition between the game and discussion. "Students weren't able to quickly make the mental transition from 'game play mode' to 'academic discussion mode'”. It was also pointed out that there were "lively conversations about strategies and experiences", but "silence" regarding the readings. Many teachers felt that they could not rely on students having done the readings before class or having attended previous lectures or classes and this sometimes made the discussion more difficult: "Not everyone had done their readings but I was able to prompt the discussion referring to the lectures and overall this seemed to be the most engaging experience of the course for the students as well as for me".

Most teachers (80\%) said that they would be happy to teach 'Capture the Market' or other games in the following year. Free-text comments ranged from the widely enthusiastic to the less convinced of the benefits of game-based learning:

"I think the game was a brilliant success, and offered students the opportunity to do something different in the classroom environment while still considering key questions around the constraints imposed on the market by various forces. At the end of each class, I was feeling good about the result (despite wishing for an extra 10-15 minutes for discussion!) and students seemed happy, engaged, and motivated. For me, this is the mark of a highly successful class, and I would be thrilled to teach this game (or other equally well designed and considered games) next year!"

"They enjoyed it, but I'm not sure if they learned more from it than they would have from the average class strategies."

The teachers' voluntary discussion forum posts were very positive, stating that it was a "highly successful class" and that the game was "a great teaching tool". One teacher noted that from a pedagogical perspective "I had 5 hours of classes today and think they were some of the most engaging hours I have spent with my students so far. (...) My students were remarkably adept at drawing out from the game to the real world and concepts from the module. Admittedly engagement with the lectures and readings could have been greater from the majority of my students. (...) However my overall impression was that this was an immensely effective class."

\section{Discussion}

The findings suggest that although the majority of the students enjoyed playing the game and felt engaged in the learning process, further improvements need to be made in order to emphasise the module's concepts and help students to grasp a deeper understanding of them. A key challenge for using games effectively lies in providing close links between the game play and the learning objectives and outcomes (Facer et al., 2004, Egenfeldt-Nielsen 2011). In the case of 'Capture the Market', creating clear links between the game and the learning objectives was challenging, owing to: the large-scale nature of the project; the high number of stakeholders; the creation of the game alongside the course content. Although the aim was to have a strong connection between the game and the course readings, the readings were still being agreed very late into the module (and game) development process, which resulted in weaker links than originally planned. 
Plass, Homer, Kinzer (2015:269) note: "if the learning and game mechanics are not tightly linked, students may be intrinsically motivated to play the game but not necessarily to learn". Observations during the post-game discussions support this argument. A reason for this could be that teachers were often more concerned with getting the game played correctly and within the allocated time rather than focusing on drawing out the links between game play and the learning objectives. Also, as Sara de Freitas (2006) notes, it is important to provide the learner with the opportunity to consider, before and after game sessions, what the learning objectives are, which facilitates opportunities for meta-cognition (reflection of the learner upon what s/he has learnt). This is confirmed by one teacher's observation that those students who had more time were more likely to draw links between the game and the learning outcomes:

"Some students struggled to identify the module concepts related to the game, but in the groups which finished play earlier and had more thinking time, they were all able to do this."

Creating a more structured and playful post-game activity may help in the future to ensure a more consistent student experience, bridge the gap between the game and the learning objectives and help students to achieve a deeper understanding.

\section{Conclusion and recommendations}

The goal of this project was to use an experiential learning activity (a game) to enhance student engagement on a large-scale inter-disciplinary course. The aim of designing 'Capture the Market' was to produce an enjoyable and well-developed game that connected to the key concepts from the module and enabled students to understand these concepts more fully through post-game discussions.

We were pleased that, as the pilot project of a new game expected to be played simultaneously across multiple classes with a large cohort of students, 'Capture the Market' worked logistically and that a large number of students and staff found the game enjoyable, engaging and connected to the course's learning outcomes.

When developing a game in a short time, it is important to ensure that all stakeholders are on board with the idea of game-based learning and that the learning outcomes are clear from the beginning. In our case, too much time spent on game design and play-testing meant that we had limited time to focus on teacher training and refining the design of the post-game discussion. We recommend expanding the training to allow time for teachers to practise running the game and managing the post-game activity, thereby creating a unified approach to delivery. This preparatory stage may help all stakeholders involved to understand better the benefits and limitations of game-based learning.

This was our first venture into serious games and we shall build on the lessons learnt to improve and support future game-based learning projects. As Berg Marklund (2015: 670) notes: "Games just as any other educational tool, require a great deal of investment and hand on guidance from teachers, who need to continuously anchor gameplay in an educational framework". 


\section{Reference list}

Berg Marklund, B. (2015) 'Novices Vs Experts; Game-Based learning and the heterogeneous classroom activities.' Proceedings of the 9th European Conference on Games-Based Learning: Nord-Trondelag University College Steinkjer Norway / [ed] Robin Munkvold and Line Kolås. Reading, UK: Academic Conferences and Publishing International Limited, 664-671. Available at: https://pdfs.semanticscholar.org/e26a/f7c10dc54f70a6c49f621af2d4640333e54d.pdf (Accessed: 30 October 2017).

Csikszentmikalyi, M (1990) Flow. The Psychology of Optimal Experience. New York: Harper Perennial.

De Freitas, S. I. (2006) 'Using games and simulations for supporting learning.' Learning, Media and Technology 31(4), 343-358.

Available at: http://dx.doi.org/10.1080/17439880601021967 (Accessed: 30 October 2017).

De Freitas, S.I. and Levene, M. (2004) 'An investigation of the use of simulations and video gaming for supporting exploratory learning and developing higher-order cognitive skills.' Paper presented at IADIS International Conference in Cognition and Exploratory Learning in the Digital Age. December 15-17, Lisbon.

Egenfeldt-Nielsen, S. (2011) 'What makes a good learning game? Going beyond Edutainment.' ELearn Magazine, February 2011. Article No. 2. Available at: DOI: 10.1111/j.1365-2729.2004.00105.x (Accessed: 30 October 2017).

Facer, K., Joiner, R., Stanton, D., Reid, J., Hull, R. and Kirk, D. (2004), Savannah: mobile gaming and learning?. Journal of Computer Assisted Learning, 20: 399-409. Available at: doi:10.1111/j.1365-2729.2004.00105.x

Felicia, P. (2011) 'Digital games in Schools: A handbook for teachers. European Schoolnet's Games in Schools Project' Available at: http://games.eun.org/upload/GIS_HANDBOOK_EN.PDF.

Joyce, A., Gerhard, P. and Debry, M. (Eds) (2009) 'How are digital games used in schools? Complete results of the study.' European Schoolnet. Available at: http://games.eun.org/upload/gis-full_report_en.pdf (Accessed: 30 October 2017).

Kafai, Y.B., and Burke, Q. (2015) 'Constructionist gaming: Understanding the benefits of making games for learning.' Educational Psychologist 50(4), 313-334. Available at: doi:10.1080/00461520.2015.1124022 (Accessed 30 October 2017).

Kirriemuir, J. and Mcfarlane, A. (2004) Literature Review in Games and Learning. A NESTA Futurelab Research report - Report 8. Available at: https://telearn.archives-ouvertes.fr/hal00190453/document (Accessed 30 October 2017). 
Kumar, R. and Lightner, R. (2007) 'Games as an interactive classroom technique: perceptions of corporate trainers, college instructors and students.'

International Journal of Teaching and Learning in Higher Education, 19(1), 53-63. Available at: http://www.isetl.org/ijtlhe/pdf//JTLHE157.pdf (Accessed 30 October 2017).

Plass, J. L., Homer, B.D. and Kinzer C.K. (2015) 'Foundations of Game-Based Learning.' Educational Psychologist, 50(4), 258-283. DOI: 10.1080/00461520.2015.1122533 (Accessed 30 October 2017).

Sardone, N. and Devlin-Scherer, R. (2016) 'Let the (Board) Games Begin: Creative Ways to Enhance Teaching and Learning.' The Clearing House: A Journal of Educational Strategies, Issues and Ideas, 89(6), 215-222.

https://doi.org/10.1080/00098655.2016.1214473 (Accessed 30 October 2017).

Vygotsky, L.S. (1978) Mind in society: The development of higher psychological processes. Cambridge, MA: Harvard University Press.

Whitton, N. (2010) Learning with Digital Games: A Practical Guide to Engaging Students in Higher Education. Routledge. 


\section{Appendix 1}

\section{Aims of the project:}

1. Increasing students' understanding of the mechanisms and incentives which operate in economic markets and the implications of liberalisation and regulation. Students' in-game choices are expected to be shaped by goals and incentives that are like those that drive capitalist market economies, such as profit maximisation, efficiency, reputation building and risk mitigation.

2. Critical thinking: Get students to question their own assumptions and pre-conceptions concerning market liberalisation and engage into the module with a more open mind.

3. Make concepts and readings more meaningful to students. The games can directly support some of the learning objectives of the course.

4. Contribute to students' development of transferable skills. Skills such as decisionmaking under time-pressure and evaluation of risk can be reinforced in this game.

5. Strengthening students' motivation and involvement with the course. Learning through games can be fun.

6. Create a game which presents a challenge for students, but which is not frustrating. 


\section{Appendix 2}

\section{Design features of 'Capture the Market'}

- Semi-cooperative (teams); this also helps with timing as it reduces the number of players to take a turn each round;

- Randomness (government interventions);

- Hidden roles and agendas (secret objective);

- Imperfect information;

- Scoring - multiple ways to win;

- Victory conditions - it is not clear who is winning until the end;

- Catch-up mechanism - some of the later rounds can allow people to catch up with double basic actions;

- 'Take that' element - take-over manoeuvre. 


\section{Appendix 3}

Questions - Student survey

Q1 - Rate the following statement: 'I enjoyed playing the Capture the Market game in class.'

Q1.1 - Please elaborate further.

Q2 - How clear were the instructions on how to play the game?

Q2.1 - Please elaborate further.

Q3 - Rate the following statements about the game: (Strongly agree, Agree, Somewhat agree, Neither agree nor disagree, Somewhat disagree)

- The game is too easy;

- The game is fun;

- I would play the game again;

- The game stimulates decision making under time pressure;

- The game is too long;

- This type of game is useful in the context of HE;

- The game provides visual metaphors of social realities;

- The game makes you think about the concepts and ideas discussed in the course.

Q4 - Rate the following statement: The 'Capture the Market' game connected with the module's framework of structure, agency and ideas. (Strongly agree, Agree, Somewhat agree, Neither agree nor disagree, Somewhat disagree, Disagree, Strongly disagree)

Q5 - Rate the following statement: The 'Capture the Market' game helped me to engage in and think about some of the key concepts from the module. (Strongly agree, Somewhat agree, Neither agree nor disagree, Somewhat disagree, Strongly disagree)

Q5.1 - Please elaborate further.

Q6 - Do you think that this game was an appropriate activity in the context of the module? (Strongly agree, Agree, Somewhat agree, Neither agree nor disagree, Somewhat disagree, Disagree, Strongly disagree)

Q6.1 - Please elaborate further.

Q7 - Would you recommend that this game be played by next year's cohort of LSE100 students? (Yes, Maybe, No)

Q7.1 - Please elaborate further.

Q8 - Any other comments? 


\section{Appendix 4}

Questions - Teacher survey

Q1 - How would you describe your experience of managing the game 'Capture the Market' and the post-game discussion in class? (Extremely difficult, Difficult, Neither easy nor difficult, Easy, Extremely easy)

Experience of managing game in class;

Experience of managing the post-game discussion in class.

Q1.1 - Please elaborate further.

Q2 - Were there any recurring issues/questions regarding the game instructions, game rules or score-sheets? Please give details.

Q3 - What aspects of the post-game discussion did you find challenging? How could this be improved?

Q4 - Rate the following statement: 'The students appeared to enjoy playing the game.'

(Strongly agree, Somewhat agree, Neither agree nor disagree, Somewhat disagree, Strongly disagree)

Q4.1 - Please elaborate further, including any direct references/quotes from students.

Q5 - Rate the following statement: 'The students engaged with their team and in the game.'

Q5.1 - Please elaborate further.

Q6 - Which post-game questions seemed to gain the biggest response?

Q7 - Do you think the game increased the students' level of engagement with the module?

(Definitely yes, Probably yes, Might or might not, Probably not, Definitely not)

Q7.1 - Please elaborate further.

Q8 - Were you able to cover all of the discussion points after the game? (Yes, No)

Q9 - Would you be happy to teach this game or other games next year? (Yes, No, Unsure)

Q9.1 - Please elaborate further.

Q10 - Were there any recurring patterns regarding game play and secret objectives?

Q11 - What were your tactics to draw out discussion and ideas?

Q12 - Any other comments? Including suggestions for improvements to the game and linking concepts to the game. 